\title{
Etanercept in the treatment of rheumatoid arthritis: clinical follow-up over one year by ultrasonography
}

\author{
Annamaria Iagnocco $\cdot$ Chiara Perella . \\ Esperanza Naredo • Gary Meenagh • Fulvia Ceccarelli • \\ Emanuela Tripodo • Stefania Basili • Guido Valesini
}

Received: 30 March 2007 / Revised: 25 July 2007 / Accepted: 30 August 2007 / Published online: 19 October 2007

(C) Clinical Rheumatology 2007

\begin{abstract}
We evaluated clinically and sonographically the effects of etanercept therapy in patients with rheumatoid arthritis (RA) over 12 months of treatment. Eighteen patients affected by RA who were non-responders or partial responders to disease modifying therapy were commenced on Etanercept treatment. Before starting therapy (T0) and at 12 months (T1), the following parameters were evaluated: erythrocyte sedimentation rate (ESR), C-reactive protein (CRP), visual analogue scale (VAS) for pain, number of painful and swollen joints, health assessment questionnaire (HAQ) and disease activity score in 28 joints (DAS 28). Musculoskeletal ultrasound (US) was performed in the following joints: second and fifth metacarpophalangeal, third interphalangeal, wrist and knee joints and a semiquantitative score ( $0-3)$ calculated and used to indicate the presence of a localised inflammatory process (synovitis, tenosynovitis, bursitis) and/or structural damage (bone erosion and cartilaginous change). An overall
\end{abstract}

\footnotetext{
A. Iagnocco $\cdot$ C. Perella $\cdot$ F. Ceccarelli $\cdot$ E. Tripodo $\cdot$ S. Basili $\cdot$

G. Valesini

Rheumatology Unit, University of Rome "La Sapienza",

Rome, Italy

E. Naredo

Department of Rheumatology, Severo Ochoa Hospital,

Madrid, Spain

G. Meenagh

Department of Rheumatology, Musgrave Park Hospital,

Belfast, UK

\author{
A. Iagnocco $(\square)$ \\ Dipartimento Clinica e Terapia Medica, Cattedra di Reumatologia, \\ "Sapienza" Università di Roma, \\ Viale del Policlinico 155, \\ Rome 00161, Italy \\ e-mail: aiagnocco@tiscali.it
}

score was calculated based on the sum of the single scores to obtain a comprehensive score indicative of the global pathological change. The US global scores significantly reduced between T0 and T1 $(p<0.0001)$. The following laboratory and clinical parameters also significantly reduced: ESR $(p<0.0001)$, CRP $(p<0.02)$, VAS $(p<0.001)$, number of total swollen joints $(p<0.001)$, number of total painful joints $(p<0.01)$, HAQ scores $(p<0.05)$ and DAS $28(p<$ $0.0001)$. A positive response to treatment with Etanercept was demonstrated both by US examination of several joints and by clinical evaluation of several parameters. US is a useful tool in the monitoring of biologic therapy in RA, assessing both inflammatory and destructive changes.

Keywords Etanercept · Follow-up · Rheumatoid arthritis . Ultrasonography

\section{Introduction}

Rheumatoid arthritis (RA) is a chronic inflammatory rheumatic disease with systemic features in which the principal targets of the inflammatory process are articular and peri-articular tissues [1]. In recent years, rheumatological research has witnessed a revolution related to the study of molecules involved in the inflammatory process and primarily the identification of the key role of tumour necrosis factor alpha $(\mathrm{TNF} \alpha)$ [2]. Its capacity to stimulate the production and secretion of pro-inflammatory cytokines, regulate the expression of adhesion molecules on endothelial cells, control the migration of leucocytes to sites of inflammation, increase the production of metalloproteinases from synovial macrophages and inhibit the production of proteoglycans has been well demonstrated to date [3]. Moreover, TNF $\alpha$ stimulates neovascularisation of synovial 
Table 1 US, clinical and laboratory parameters

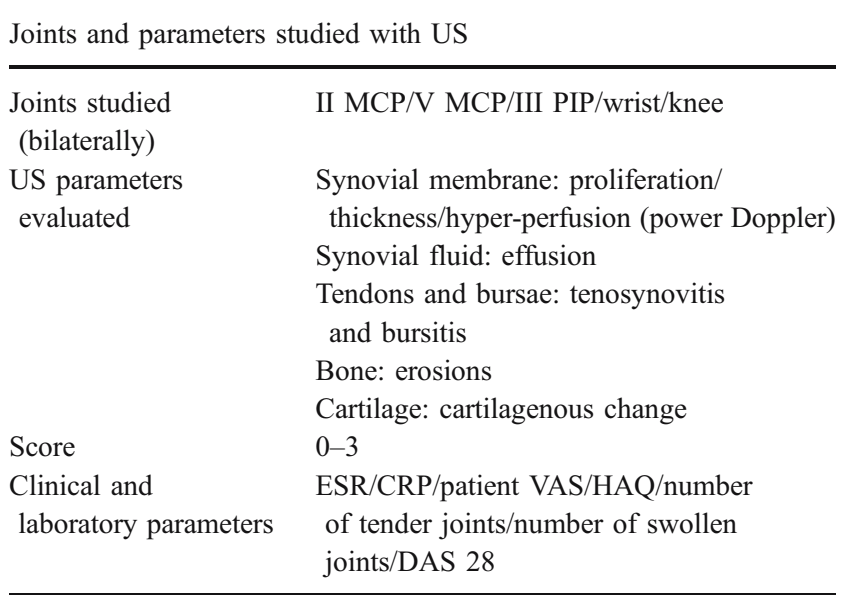

tissue, a phenomenon which correlates with the level of local inflammatory activity [4]. In essence, $\mathrm{TNF} \alpha$ represents a key molecule in the activation and perpetuation of the inflammatory process within joints and systemically in RA, leading subsequently to joint erosion and permanent structural damage [5].

In light of the fundamental role played by such cytokine in the pathogenesis of the inflammation seen in RA, research has concentrated on implementing new pharmacological strategies to directly antagonise $\mathrm{TNF} \alpha$, with the aim of blocking or slowing down its molecular impact [6-9]. Enbrel is one agent which inhibits the soluble $\mathrm{TNF} \alpha$ receptor. Randomised double-blind control trials have demonstrated the safety, tolerability and the reduction in disease activity of anti-TNF $\alpha$ therapy [10]. In RA, TNF $\alpha$ blockade results in an improvement in the number and severity of joints involved, the indices of inflammation and the parameters of disease activity both compared to placebo and compared with other disease-modifying drugs particularly methotrexate [11].

Ultrasound (US) of joints and tendons is a useful imaging method in the diagnosis and follow-up of rheumatic disorders [12]. It can demonstrate changes in the soft tissues particularly hypertrophy of the synovial membrane, joint inflammation, tenosynovitis and bursitis [13]. Moreover, with the advent of power Doppler, US is capable of revealing the extent of synovial flow in presence of neovascularisation and therefore the increase in perfusion of the synovial membrane in cases of synovitis [14]. As a result, it is now possible to demonstrate the level of inflammatory activity present within synovial tissue, differentiating between acute and chronic inflammation [15]. US is of particular benefit when searching for bone erosion and cartilaginous change in early phases of the disease process, thereby allowing a diagnosis to be confirmed and the progression of the disease to be followed [16]. Furthermore, multiplanar scanning permits examination of superficial areas which cannot be studied satisfactorily with conventional X-ray $[17,18]$.

Only a few studies have been published to date in which the response to biologic therapy has been followed. The results obtained have, however, underlined the potential role for US in the monitoring treatment response [19-21]. Unfortunately, the small number of patients and the brevity of follow-up make further studies necessary.

The object of this study was to evaluate, by means of US, the effects of etanercept therapy in RA after 1 year and correlate these findings with clinical and laboratory indices.

\section{Materials and methods}

Eighteen consecutive patients, 4 men and 14 women, receiving etanercept ( $25 \mathrm{mg}$ subcutaneously twice weekly) plus methotrexate (10-15 mg weekly) and/or hydroxychloroquine (400 $\mathrm{mg}$ daily) and/or salazopyrin (2 g daily) and non-steroid anti-inflammatories (diclofenac 50-100 mg daily or indomethacin 50-100 mg daily or nimesulide 100 $200 \mathrm{mg}$ daily) and steroids (methylprednisolone 4-8 mg daily) for RA and fulfilling the American Rheumatology Association diagnostic criteria were studied. All patients were non-responders or partial responders to diseasemodifying therapy. The mean age was 50.8 (range 31-69) with mean disease duration of 13.05 years (range 3-31). This study was conducted only in one center, the Rheumatology Unit of "Sapienza" University of Rome, in compliance with the protocol and good clinical practices, following the routinely monitoring procedures performed in our unit for patients with arthritis.

Table 2 Subdivision of all US, clinical and laboratory parameters into four classes of severity

\begin{tabular}{llllllll}
\hline Class & US & ESR & VAS & HAQ & No pain joints & No swollen joints & DAS 28 \\
\hline I & $<10$ & $\leq 10$ & $\leq 30$ & $<0.5$ & $\leq 6$ & $\leq 3$ & $<2.6$ \\
II & $\geq 10<20$ & $>10<25$ & $>30<55$ & $\geq 0.5<1$ & $>6 \leq 15$ & $>3 \leq 7$ & $\geq 2.6<3.2$ \\
III & $\geq 20<30$ & $\geq 25<40$ & $\geq 55<80$ & $\geq 1<1.5$ & $>15 \leq 24$ & $>7 \leq 10$ & $>3.2<5.1$ \\
IV & $\geq 30$ & $\geq 40$ & $\geq 80$ & $\geq 1.5$ & $>24$ & $>10$ & $\geq 5.1$ \\
\hline
\end{tabular}


Table 3 Results for all patients at T0 and T1

\begin{tabular}{|c|c|c|c|c|c|c|c|c|c|c|c|c|c|c|c|c|}
\hline Patients & $\begin{array}{l}\text { US } \\
\text { T0 }\end{array}$ & $\begin{array}{l}\text { US } \\
\mathrm{T} 1\end{array}$ & $\begin{array}{l}\text { ESR } \\
\text { T0 }\end{array}$ & $\begin{array}{l}\text { ESR } \\
\mathrm{T} 1\end{array}$ & $\begin{array}{l}\text { CRP } \\
\text { T0 }\end{array}$ & $\begin{array}{l}\text { CRP } \\
\text { T1 }\end{array}$ & $\begin{array}{l}\text { VAS } \\
\text { T0 }\end{array}$ & $\begin{array}{l}\text { VAS } \\
\mathrm{T} 1\end{array}$ & $\begin{array}{l}\text { HAQ } \\
\text { T0 }\end{array}$ & $\begin{array}{l}\text { HAQ } \\
\mathrm{T} 1\end{array}$ & $\begin{array}{l}\text { Pain } \\
\text { T0 }\end{array}$ & $\begin{array}{l}\text { Pain } \\
\text { T1 }\end{array}$ & $\begin{array}{l}\text { Swel } \\
\text { T0 }\end{array}$ & $\begin{array}{l}\text { Swel } \\
\mathrm{T} 1\end{array}$ & $\begin{array}{l}\text { DAS } \\
28 \mathrm{~T} 0\end{array}$ & $\begin{array}{l}\text { DAS } \\
28 \mathrm{~T} 1\end{array}$ \\
\hline $\mathrm{BC}$ & 34 & 26 & 16 & 19 & neg & neg & 75 & 68 & 1.25 & 2 & 13 & 15 & 4 & 3 & 5.57 & 5.67 \\
\hline $\mathrm{BL}$ & 18 & 8 & 30 & 27 & pos & neg & 67 & 21 & 2 & 1 & 21 & 1 & 8 & 3 & 6.75 & 3.77 \\
\hline $\mathrm{BN}$ & 21 & 13 & 43 & 5 & pos & pos & 40 & 30 & 1.38 & 0.75 & 8 & 10 & 7 & 4 & 4.62 & 4.43 \\
\hline $\mathrm{CP}$ & 27 & 13 & 22 & 11 & pos & pos & 95 & 53 & 1.625 & 1 & 25 & 6 & 16 & 6 & 6.92 & 4.15 \\
\hline $\mathrm{CF}$ & 18 & 12 & 42 & 19 & pos & neg & 55 & 40 & 0.5 & 0.5 & 16 & 10 & 5 & 5 & 6.25 & 5.02 \\
\hline $\mathrm{CP}$ & 17 & 6 & 40 & 18 & neg & neg & 20 & 10 & 0.125 & 0.125 & 1 & 1 & 1 & 0 & 3.7 & 2.72 \\
\hline $\mathrm{CA}$ & 27 & 16 & 45 & 15 & pos & neg & 81 & 36 & 1.125 & 0.625 & 14 & 9 & 6 & 0 & 6.58 & 4.08 \\
\hline $\mathrm{DE}$ & 21 & 8 & 10 & 8 & neg & neg & 70 & 35 & 1.875 & 0.25 & 20 & 14 & 6 & 0 & 5.78 & 4.04 \\
\hline $\mathrm{DM}$ & 31 & 7 & 30 & 17 & pos & neg & 70 & 0 & 1.5 & 0.625 & 15 & 0 & 4 & 0 & 5.32 & 1.98 \\
\hline LR & 21 & 4 & 62 & 18 & pos & pos & 73 & 40 & 2 & 2 & 27 & 11 & 11 & 8 & 7.88 & 5.23 \\
\hline MS & 20 & 12 & 28 & 22 & neg & neg & 40 & 33 & 1 & 1 & 22 & 10 & 12 & 8 & 6.42 & 5.34 \\
\hline PP & 17 & 8 & 40 & 33 & pos & neg & 100 & 50 & 1.5 & 1.125 & 2 & 4 & 2 & 1 & 5.17 & 4.55 \\
\hline $\mathrm{PA}$ & 25 & 8 & 21 & 11 & neg & neg & 48 & 20 & 1 & 0 & 1 & 0 & 2 & 0 & 3.61 & 1.92 \\
\hline PL & 21 & 16 & 76 & 50 & pos & neg & 70 & 67 & 1.375 & 1 & 6 & 1 & 4 & 0 & 5.94 & 4.24 \\
\hline PS & 15 & 5 & 32 & 10 & neg & neg & 50 & 0 & 1.25 & 0 & 19 & 3 & 11 & 1 & 6.92 & 2.86 \\
\hline SM & 30 & 13 & 40 & 22 & pos & neg & 90 & 27 & 2 & 5 & 29 & 4 & 12 & 1 & 7.79 & 5.1 \\
\hline
\end{tabular}

\section{US examination}

In all patients, the following joints were studied bilaterally: second and fifth metacarpophalangeal (MCPs), third interphalangeal (PIP), wrist and knee. The joints evaluated were chosen because they are commonly involved in RA, and they can be reliably assessed by US. The US examination was performed using a Philips/HP Image Point HX machine with a $10-\mathrm{MHz}$ linear probe for knee joints and a 14-MHz probe for the hands and wrists. In addition, power Doppler was used with the following settings: PRF varying from $700-1,000 \mathrm{~Hz}$ (according to the joint studied) gain 18-30 dB, low filter. The examination was performed before the initiation of etanercept (T0) and after 52 weeks (T1). The US study was performed by an experienced rheumatologist sonographer (AI) who was blinded to the clinical and laboratory findings in each patient.

In every joint, a multiplanar scanning technique $[17,18]$ was used and the presence of inflammation documented in joints and or peri-articular tissues (joint effusion, synovial proliferation, hyperaemia in the synovial tissue, tenosynovitis and bursitis) together with the presence of permanent damage (bone erosions and cartilaginous abnormalities). The changes within each articular and peri-articular structure were recorded as being present in accordance with the reported definitions in the literature [22, 23]. For all the changes, a semiquantitative score $(0-3)$ was used for each structure examined indicating the degree of inflammatory activity and structural damage $(0=$ normal; $1=$ mild change; $2=$ moderate change; $3=$ severe change) and the subsequent summed total used as an indicator of global change at each time point. An increase in score from T0 to $\mathrm{T} 1$ was considered indicative of global deterioration in the pathological process, whilst a reduction was indicative of an overall improvement.

\section{Clinical evaluation}

The clinical and laboratory parameters measured at $\mathrm{T} 0$ and $\mathrm{T} 1$ are listed in Table 1.
Table 4 Results (mean and median) at $\mathrm{T} 0$ and $\mathrm{T} 1$

$t$ Test for dependent samples. Data are presented as mean \pm SD or median (25th-75th percentile)

${ }^{\text {a }}$ Wilcoxon signed rank test

${ }^{\mathrm{b}}$ Chi-square test

\begin{tabular}{llll}
\hline Variable & T0 $(n=18)$ & $p$ & T1 $(n=18)$ \\
\hline Age (years) & $50.8(31-69)$ & $>0.05$ & $51.8(32-70)$ \\
US $^{\mathrm{a}}$ & $21(18-27)$ & $<0.0001$ & $11.2(8-13)$ \\
$\mathrm{CRP}>0.5 \mathrm{mg} / \mathrm{dl} n(\%)^{\mathrm{b}}$ & $8(44)$ & $<0.02$ & $3(17)$ \\
ESR $_{\text {VAS }}^{\mathrm{a}}$ & $35 \pm 17$ & $<0.0001$ & $19 \pm 12$ \\
$\mathrm{HAQ}^{\mathrm{a}}$ & $70.0(50-70)$ & $<0.001$ & $33.5(21-50)$ \\
Painful joints & $1.38(1,12-1,87)$ & $<0.05$ & $1.03(0.37-1.12)$ \\
Swollen joints & $14.5(8-21)$ & $<0.01$ & $6.5(1-10)$ \\
DAS 28 & $6(4-11)$ & $<0.001$ & $1(0-5)$ \\
& $5.9 \pm 1.2$ & $<0.0001$ & $4.1 \pm 1.4$ \\
\hline
\end{tabular}


For each US, clinical and laboratory parameter 4 degrees of severity were assigned to the changes to grade the effects of therapy (Table 2).

Statistical analysis

Data were reported as mean values \pm standard deviations or as median values with the inter-quartile ranges in cases of variables with non-standard distribution. Appropriate statistical tests were used to analyse the data. In particular, normally distributed variables were analysed using the Student's $t$ test for unpaired data and Pearson correlation. For all other nonparametric data, the following tests were used (Mann-Whitney $U$ test, Kruskal-Wallis, analysis of variance and Spearman correlation test). The differences in percentages were analysed using the chi-squared test. Statistical significance was taken at a $p$ value $<0.05$. All calculations were made using IBM 'Statistica' (StatSoft, Tulsa, OK, USA) software.

\section{Results}

The results of this study are summarised in Tables 3 and 4 and Fig. 1.

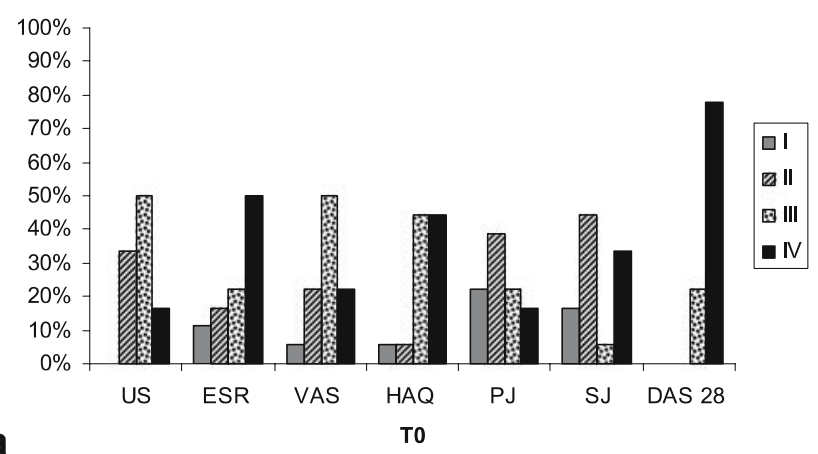

a

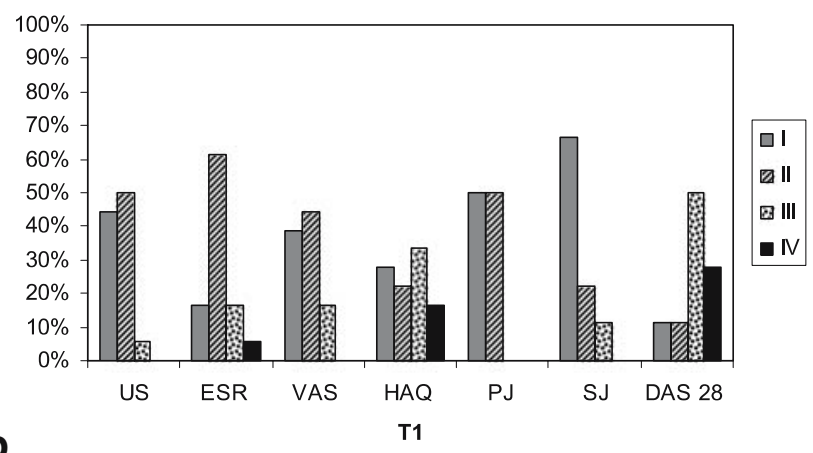

Fig. 1 Subdivision into classes of severity of the changes seen in all the parameters evaluated. A response to therapy was demonstrated in patients who had more severe changes (classes III and IV) at T0 and less severe changes (classes I and II) at T1. The $p$ values were respectively: US global score, $p<0.0001$; CRP, $p<0.02$; ESR, $p<0.0001$; VAS, $p<0.001$; HAQ, $p<0.05$; number of total painful joints, $p<0.01$; number of total swollen joints, $p<0.001$; DAS 28, $p<0.0001$
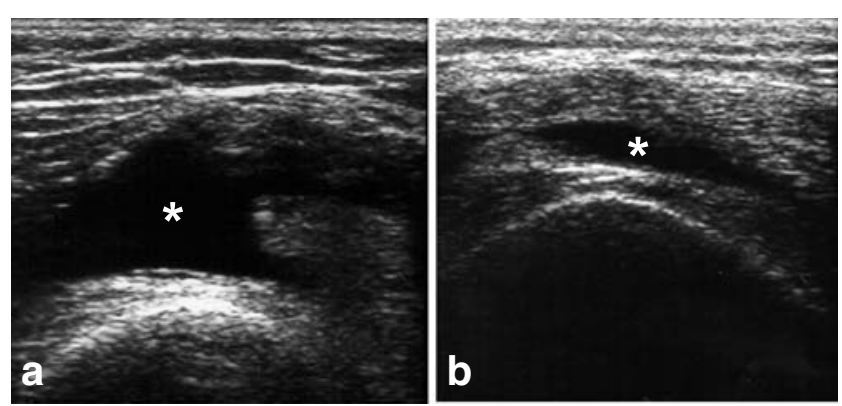

Fig. 2 Knee US. Supra-patellar transverse scan. a At T0, an effusion (*) and synovial proliferation were present in the supra-patellar bursa. b At T1, a reduction in the size of effusion $\left(^{*}\right)$ and synovial proliferation was seen

US evaluation demonstrated a significant reduction (median changes $=-10 ; p<0.0001$ ) in the US global score (sum of the semiquantitative score or each structure examined indicating the degree of inflammatory activity and structural damage) from T0 to T1. In particular, before starting therapy, the median US global score was 21 [interquartile ranges (IQR), 18-27] and after 1 year of etanercept therapy was reduced to 11.2 (IQR, 8-13). The evaluation of the knee joint is shown in Fig. 2 at T0 and T1.

CRP values significantly decreased after 12 months. Of the 11 patients with an elevated CRP at baseline, eight had normal values at $\mathrm{T} 1$ and three remained high $(p<0.02)$. Erythrocyte sedimentation rate (ESR) also fell significantly $(p<0.0001)$ from a mean of $35( \pm 17 \mathrm{~mm} / \mathrm{h})$ at $\mathrm{T} 0$ to 19 $(+\mathrm{SD} 12)$ at T1. The median VAS fell significantly $(p<$ 0.001 ) from 70 (IQR, 50-70) at T0 to 33.5 (IQR, 21-50) at T1. Median Health assessment questionnaire (HAQ) values fell significantly $(p<0.05)$ from 1.38 (IQR, 1.12-1.87) at baseline to 1.03 (IQR, 0.37-1.12) at 1 year. The number of painful total joints changed significantly $(p<0.01)$ from a median of 14.5 (IQR, 8-21) at baseline to 6.5 (IQR, 1-10) at T1. Similarly, the median number of total swollen joints also fell significantly $(p<0.001)$ from 6 (IQR, 4-11) at baseline to 1 (IQR, 0-5) at T1. The mean DAS 28 scores fell significantly $(p<0.0001)$ from $5.9( \pm 1 \mathrm{SD}, 1.2)$ to 4.1 $( \pm 1 \mathrm{SD}, 1.4)$ at 1 year. The subclasses in the degree of change demonstrated in all the parameters evaluated more severe involvement (III, IV) at baseline and less severe degrees of involvement (I, II) at 1 year.

\section{Discussion}

In recent years, the role of US as a diagnostic tool and as a mode of monitoring therapy in rheumatic disease has been progressively confirmed. It has enabled the exploration of various articular and peri-articular structures [24] together with local neovascularisation, thanks to power Doppler. It is now possible to identify and monitor the progression of active inflammation. 
To date, very few scientific papers have documented the use of US in the monitoring of biologic therapy. D'Agostino et al. [25] demonstrated a significant reduction in synovial perfusion within the Achilles insertion in two patients treated with infliximab ( $3 \mathrm{mg} / \mathrm{kg}$ at time 0,2 and 6 weeks) after 14 weeks. Ribbens et al. [26] subsequently showed a clear reduction in synovitis and power Doppler signal in the small joints of the hand in 11 patients treated with infliximab for 6 weeks. Furthermore, in 2004, a randomised placebocontrolled trial compared radiographic methods in the evaluation of the joints of the hand and feet with US in patients with RA treated with methotrexate and infliximab or placebo [27]. This study showed a reduction in inflammation and retardation of joint destruction in patients who had been randomised to receive infliximab both in terms of radiographic and sonographic findings. At present the effects of etanercept in the treatment of patients with RA has not been extensively studied.

Hau et al. [28] studied the effects of etanercept ( $25 \mathrm{mg} \times 2 /$ week) in five patients after 1 month of therapy and showed a significant reduction in synovial perfusion with power Doppler at the level of the second MCP joint. A further study evaluated the changes in synovial perfusion in 11 patients with RA treated with etanercept $(50 \mathrm{mg} /$ week) at the level of the wrist and the MCP joints and documented an important initial reduction in perfusion after 1 week of treatment [29]. More recently, 12 patients with RA and eight with psoriatic arthritis and knee synovitis treated with etanercept had a significant reduction in power Doppler signal which correlated with reductions in indices of disease activity including ESR and CRP. This improvement in synovitis was maintained for 12 months of biologic therapy and was confirmed by the reduction in thickness of the synovial membrane sonographically [30].

The results of these studies underline the emerging role of greyscale US and power/color/contrast-enhanced Doppler in the evaluation of anti-inflammatory efficacy of biologic therapy with infliximab and etanercept in chronic arthritis, most notably RA [31-35]. Unfortunately, these studies have been limited by the number of patients evaluated together with the short period of follow-up. With this in mind, our study followed 18 patients with RA treated with etanercept and monitored sonographically, clinically and serologically over a 52-week period. We have clearly demonstrated a significant reduction in US score calculated on the joint examination. The importance of these data was confirmed by a parallel reduction in all the clinical and laboratory indices of disease activity. Furthermore, it seems that the response of US parameters is greater than DAS 28 . The results of our study are supportive of those presented in other reports where US was used to monitor disease activity. We were able, however, to demonstrate this in a wider range of anatomical targets than in previous studies [28-30]. To our knowledge, this study represents the first attempt to investigate the effects of biologic therapy on multiple parameters in various joints affected by a chronic arthropathy. Then, US appears to be a valuable tool for the assessment of the response to treatment in RA, and it has many advantages over other diagnostic methods and clinical indices of disease activity such as the low cost, noninvasiveness and possibility of a contemporaneous assessment of inflammatory and structural changes. The close relationship between our US findings and the standardly used clinical and serological indices of disease activity strengthen further the case for using US as one of the investigations of choice in the monitoring of biologic therapy in RA [36-46].

\section{References}

1. Arnett FC, Keat ACS (1997) Spondyloarthropathies. In: Klippel JH, Dieppe PA (eds) Rheumatology. Mosby, St. Louis, pp 10.120.12

2. Macias I, Garcia-Perez S, Ruiz-Tudela M, Medina F, Chozas N, Giron-Gonzalez JA (2005) Modification of pro- and antiinflammatory cytokines and vascular-related molecules by tumor necrosis factor-a blockade in patients with rheumatoid arthritis. J Rheumatol 32:2102-2108

3. Feldmann M, Brennan FM, Foxwell BM, Maini RN (2001) The role of TNF alpha and IL-1 in rheumatoid arthritis. Curr Dir Autoimmun 3:188-199

4. Taylor PC, Sivakumar B (2005) Hypoxia and angiogenesis in rheumatoid arthritis. Curr Opin Rheumatol 17:293-298

5. Ritchlin CT (2004) Mechanisms of erosion in rheumatoid arthritis. J Rheumatol 31:1229-1237

6. Furst DE, Breedveld FC, Kalden JR, Smolen JS, Antoni CE, Bijlsma JWJ et al (2002) Updated consesus statement on biological agents for the treatment of rheumatoid arthritis and other rheumatic diseases. Ann Rheum Dis 61(Suppl II):ii2-ii7

7. Bresnihan B (2002) Effects of anakinra on clinical and radiological outcomes in rheumatoid arthritis. Ann Rheum Dis 61(Suppl II):ii74-ii77

8. Maini RN, Taylor PC, Paleolog E (1999) Anti-tumor necrosis factor specific antibody (infliximab) treatment provides insights into the pathophysiology of rheumatoid arthritis. Ann Rheum Dis 58(Suppl I):I156-II60

9. Kruithof E, Van den Bosch F, Baeten D, Herssens A, de Keyser F, Mielants H, Veys EM (2002) Repeated infusions of infliximab, a chimeric anti-TNF $\alpha$ monoclonal antibody, in patients with active spondyloarthropathy: one year follow up. Ann Rheum Dis 61: 207-212

10. Van der Heijde D, Klareskog L, Singh A, Tornero J, Melo-Gomes J, Codreanu C et al (2006) Patient reported outcomes in a trial of combination therapy with etanercept and methotrexate for rheumatoid arthritis: the TEMPO trial. Ann Rheum Dis 65 (3):328-334

11. Moreland L (2004) Etanercept and methotrexate combination in rheumatoid arthritis. Curr Rheumatol Rep 6(5):333

12. Wakefield RJ, Gibbon WW, Emery P (1999) The current status of ultrasonography in rheumatology. Rheumatology 38:195-198

13. Alarcon GS, Lopex-Ben R, Moreland LW (2002) High-resolution ultrasound for the study of target joints in rheumatoid arthritis. Arthritis Rheum 46:1969-1980 
14. Newman JS, Laing TJ, McCarthy CJ, Adler RS (1996) Power Dopppler sonography of synovitis: assessment of therapeutic response-preliminary observations. Radiology 198:582-584

15. Walther M, Harms H, Krenn V, Radke S, Faehndrich TP, Gohlke F (2001) Correlation of power Doppler sonography with vascularity of the synovial tissue of the knee joint in patients with osteoarthritis and rheumatoid arthritis. Arthritis Rheum 44:331-338

16. Wakefield RJ, Gibbon WW, Conaghan PG, O'Connor P, McGonagle D, Pease C et al (2000) The value of sonography in the detection of bone erosions in patients with rheumatoid arthritis: a comparison with conventional radiography. Arthritis Rheum 43:2762-2770

17. Backhaus M, Burmester G-R, Gerber T, Grassi W, Machold KP, Swen WA et al (2001) Guidelines for musculoskeletal ultrasound in rheumatology. Ann Rheum Dis 60:641-649

18. Schmidt WA, Schmidt H, Schicke B, Gromnica-Ihle E (2004) Standard reference values for musculoskeletal ultrasonography. Ann Rheum Dis 63(8):988-994

19. Balint PV, Kane D, Wilson H (2002) Ultrasonography of entheseal insertions in the lower limb in spondyloarthropathy. Ann Rheum Dis 61:905-910

20. Frediani B, Falsetti P, Storri L, Allegri A, Bisogno S, Baldi F et al (2002) Ultrasound and clinical evaluation of quadricipital tendon enthesitis in patients with psoriatic arthritis and rheumatoid arthritis. Clin Rheumatol 21:203-206

21. Naranjo A, Marrero-Pulido T, Ojeda S, Francisco F, Erausquin C, Rua-Figueroa I et al (2002) Abnormal sonographic findings in the asymptomatic arthritic shoulder. Scand J Rheumatol 31(1):17-21

22. Wakefield RJ, Balint PV, Szkudlarek M, Filippucci E, Backhaus M, D'Agostino MA et al OMERACT 7 Special Interest Group (2005) Musculoskeletal ultrasound including definitions for ultrasonographic pathology. J Rheumatol 32(12):2485-2487

23. Iagnocco A, Ossandon A, Coari G, Conti F, Priori R, Alessandri C et al (2004) Wrist joint involvement in systemic lupus erythematosus. An ultrasonographic study. Clin Exp Rheumatol 22(5): 621-624

24. Szkudlarek M, Court-Payen M, Strandberg C, Klarlund M, Klausen T, Østergaard M (2001) Power doppler ultrasonography for assessment of synovitis in the metacarpophalangeal joints of patients with rheumatoid arthritis. Arthritis Rheum 44(9): 2018-2023

25. D'Agostino MA, Breban M, Said-Nahal R, Dougados M (2002) Refractory inflammatory heel pain in spondylarthropathy: a significant response to infliximab documented by ultrasound. Arthritis Rheum 46(3):840-841

26. Ribbens C, Andre B, Marcelis S, Kaye O, Mathy L, Bonnet V et al (2003) Rheumatoid hand joint synovitis: gray-scale and power Doppler US quantifications following anti-tumor necrosis factoralpha treatment: pilot study. Radiology 229(2):562-569

27. Taylor PC, Steuer A, Gruber J, McClinton C, Cosgrove DO, Blomley $\mathrm{MJ}$ et al (2005) Ultrasonographic and radiographic results from a two-year controlled trial of immediate or one-yeardelayed addition of infliximab to ongoing methotrexate therapy in patients with erosive early rheumatoid arthritis. Arthritis Rheum $54(1): 47-53$

28. Hau M, Kneitz C, Tony HP, Keberle M, Jahans R, Jenett M (2002) High resolution ultrasound detects a decrease in pannus vascularisation of small finger joints in patients with rheumatoid arthritis. Ann Rheum Dis 61:55-58

29. Terslev L, Torp-Pedersen S, Qvistgaard E, Kristoffersen H, Rogind H, Danneskiold-Samsoe B et al (2003) Effects of treatment with etanercept (Enbrel, TNRF:Fc) on rheumatoid arthritis evaluated by Doppler ultrasonography. Ann Rheum Dis 62:178-181
30. Fiocco U, Ferro F, Vezzu M, Cozzi L, Checchetto C, Sfriso P et al (2005) Rheumatoid and psoriatic knee synovitis: clinical, grey scale, and power Doppler ultrasound assessment of the response to etanercept. Ann Rheum Dis 64(6):899-905

31. Cardinal E, Lafortune M, Burns P (1996) Power Doppler us in synovitis: reality or artifact? Radiology 200(3):868-869

32. Klauser A, Frauscher F, Schirmer M, Halpern E, Pallwein L, Herold $M$ et al (2002) The value of contrast-enhanced color Doppler ultrasound in the detection of vascularization of finger joints in patients with rheumatoid arthritis. Arthritis Rheum 46(3):647-653

33. Klocke R, Glew D, Cox N, Blake DR (2001) Sonographic erosions of the rheumatoid little toe. Ann Rheum Dis 60:896-904

34. Magarelli N, Guglielmi G, Di Matteo L, Tartaro A, Mattei PA, Bonomo L (2001) Diagnostic utility of an echo-contrast agent in patients with synovitis using power Doppler ultrasound: a preliminary study with comparison to contrast-enhanced MRI. Eur Radiol 11:1039-1046

35. Stone M, Bergin D, Whelan B, Maher M, Murray J, McCarthy C (2001) Power Doppler ultrasound assessment of rheumatoid hand synovitis. J Rheumatol 28(9):1979-1982

36. St Clair EW (2002) Infliximab treatment for rheumatic disease: clinical and radiological efficacy. Ann Rheum Dis 61(Suppl II): ii67-ii69

37. Weinblatt ME, Keystone EC, Furst DE, Moreland LW, Weisman MH, Biurbara CA et al (2003) Adalimumab, a fully human antitumor necrosis factor $\alpha$ monoclonal antibody, for the treatment of rheumatoid arthritis in patients taking concomitant methotrexate: the ARMADA trial. Arthritis Rheum 48:35-45

38. Antoni C, Dechant C, Hanns-Martin Lorenz PD, Wendler J, Ogilvie A, Lueftl M et al (2002) Open-label study of infliximab treatment for psoriatic arthritis: clinical and magnetic resonance imaging measurements of reduction of inflammation. Arthritis Rheum 47(5):506-512

39. Braun J, Sieper J, Breban M, Collantes-Estevez E, Davis J, Inman $R$ et al (2002) Anti-tumor necrosis factor $\alpha$ therapy for ankylosing spondylitis: international experience. Ann Rheum Dis 61(Suppl III):iii51-iii60

40. Charles PJ, Smeenk RTJ, De Jong J, Feldmann M, Maini RN (2000) Assessment of antibodies to double-stranded DNA induced in rheumatoid arthritis patients following treatment with infliximab, a monoclonal antibody to tumor necrosis factor $\alpha$. Arthritis Rheum 43(11):2383-2390

41. Garrison L, McDonnell ND (1999) Etanercept: therapeutic use in patients with rheumatoid arthritis. Ann Rheum Dis 58(suppl I): I65-I69

42. Jones G, Halbert J, Crotty M, Shanahan EM, Batterham M, Ahern M (2003) The effect of treatment on radiological progression in rheumatoid arthritis: a systematic review of randomized placebocontrolled trials. Rheumatology 42:6-13

43. Rau R (2002) Adalimumab (a fully human anti-tumor necrosis factor $\alpha$ monoclonal antibody) in the treatment of active rheumatoid arthritis: the initial results of five trials. Ann Rheum Dis 61(Suppl II):ii70-ii73

44. Sokka T, Pincus T (2003) Elegibility of patients in routine care for major clinical trials of anti-tumor necrosis factor $\alpha$ agents in rheumatoid arthritis. Arthritis Rheum 48:313-318

45. St Clair EW, Wagner CL, Fasanmade AA, Wang B, Schaible T, Kavanaugh A et al (2002) The relationship of serum infliximab concentrations to clinical improvement in rheumatoid arthritis. Arthritis Rheum 46:1451-1459

46. Ulfgren AK, Andersson U, Engstromm M, Klareskog L, Maini RN, Taylor PC (2000) Systemic anti-tumor necrosis factor $\alpha$ therapy in rheumatoid arthritis down-regulates synovial tumor necrosis $\alpha$ synthesis. Arthritis Rheum 43:2391-2396 